\title{
Vertical Distribution of Intertidal Seaweeds as Related to Patterns of Submersion and Emersion
}

\author{
Louis D. Druehl ${ }^{1}$ and John M. Green ${ }^{2}$ \\ ${ }^{1}$ Department of Biological Sciences, Simon Fraser University, Burnaby, B. C., Canada V5A 1S6 \\ ${ }^{2}$ Department of Biology and Marine Science Research Laboratory, Memorial University, St. Johns, Newfoundland, Canada \\ A1B $3 \times 9$
}

\begin{abstract}
Effects of waves on aspects of tides which determine the degree of stress to which intertidal organisms are subjected are assessed and quantified. The difference between actual and predicted time of tidal flooding and ebbing under different wave height conditions was measured on 3 distinct, adjacent topographies along a wave-exposed shore on the southwest coast of Vancouver Island, B. C., Canada. Tidal curves which accurately reflected submersion/emersion events were then generated for the 3 transects. Vertical distributions of the conspicuous intertidal algal species were determined along the transects, and related to the empirically determined tide curves. Wave action caused changes in submersion/emersion events from those predicted by tidal data; the extent of these changes depended upon topography and season. Algal distributions on the three transects over 6 yr showed a significant correlation with some aspects of their submersion/emersion histories, indicating that these events are important in influencing the vertical distribution of intertidal seaweeds.
\end{abstract}

\section{INTRODUCTION}

Until recently, biologists presumed that the vertical distribution of intertidal macrophytes reflected their physiological tolerances to atmospheric conditions during periods of emersion (Doty, 1957). The physical features generally thought to be responsible were insolation, temperature, desiccation, and precipitation (Lewis, 1964). The severity of these features was considered to be a function of the emersion and submersion history of the intertidal region, and this history in turn to be a reflection of local tidal cycles.

Presently, marine biologists emphasize biological interactions (e. g. grazing, shading, space competition) as being major factors in determining the vertical limits of intertidal organisms. This change in approach evolved mainly following the work of Connell (1961), and is illustrated by the field experiments of Paine and Vadas (1969), Dayton (1975), Paine (1979), Lubchenco (1980) and others.

Carefoot (1977) and Lewis (1977) have suggested that the vertical distribution of intertidal organisms probably results from a combination of biological interaction and physiological tolerance. As Lewis (1977) has pointed out, however, the relationship between vertical distributions and the emersion and submersion history of the shore is poorly understood.

At least 3 aspects of the tides have been suggested as operative in determining the degree of physical stress on intertidal organisms. Hewatt (1937) proposed that the accumulated time spent emerged or submerged, and the number of times an organism is emerged or submerged, are important in determining the vertical position of intertidal biota. Doty (1946) suggested that the duration of the single greatest submergence or emergence was important in determining biotic distribution. These ideas have been tested, in part, by correlating observed distributions with predicted tidal features (e. g. Doty, 1946; Underwood, 1978). A possible error in this approach is that the actual emersion/ submersion history of the intertidal region may differ from that indicated by the predicted or recorded tides, as a result of wave effects. The effects of waves on elevating or lowering the vertical distributions of various intertidal organisms are well documented (e. g. Lewis, 1964; Jones and Demetropoulos, 1968), but to our knowledge no attempt has been made to elucidate the effects waves have on those aspects of tides that determine the degree of stress to which an intertidal organism is subjected. 
Our study has attempted to clarify 3 questions concerned with the distribution of organisms in the intertidal zone: (1) What are the relations between the actual submersion/emersion histories of 3 contiguous topographies with different slopes on a wave-exposed shore; (2) what are the relations between the upper and lower limits of seaweeds on the 3 topographies and how do they vary from one year to another; (3) what are the relations between upper and lower distribution limits of the seaweeds and the submersion/emersion histories of the 3 topographies?

\section{MATERIALS AND METHODS}

Our basic approach was to determine the difference between the actual and predicted time of tidal flooding and ebbing under different wave height conditions on 3 common coastal topographies: a channel, a flat, and a point. These 3 topographies were included in $50 \mathrm{~m}$ of shoreline along Botany Beach $\left(48^{\circ} 33^{\prime} \mathrm{N}, 124^{\circ} 25^{\prime} \mathrm{W}\right)$ on the southwest coast of Vancouver Island, British Columbia, Canada. Their exposure was west-north-west, the same orientation as the prevailing swell.

Transects were surveyed using a $\mathrm{K}$ and $\mathrm{E}$ Paragon transit, Zeiss self-levelling level, steel measuring tape, and a stadia rod. Markers were anchored in rock along each transect at $0.8,1.4,1.7,2.3$, and $2.9 \mathrm{~m}$ above 0 tide level. These tide levels were projected from an established bench mark.

Wave heights were recorded twice daily almost continuously during 1966. Wave height was measured from the shore with a stadia rod using the horizon as reference level.

Actual times and durations of emergence and submergence for different levels along the 3 transects were determined concurrently using submersion/ emersion sensors (Druehl and Green, 1970). The relation between sea level and wave height was found by determining the difference between the actual sea level, as determined by the submersion/emersion sensors, and the predicted level for the 3 transects. The predicted levels were taken from 6-min interval tidal predictions (Canadian Hydrographic Office, Ottawa, pers. comm.).

Regression lines relating sea level to wave height were developed for each transect, and these were then employed in correcting the predicted tide curves for the 3 different topographies. The corrected tide curves were used to determine the accumulated time submerged, total number of emergences and submergences, and duration of the single greatest emergence and submergence throughout the vertical extent of the intertidal zone on the 3 transects. These calculations were made for the May 1 - June 14 period, and for 4 3-mo periods during 1966. However, due to the similarity in trends between transects and seasons, only the May 1 - June 14 data are presented, with the exception of data on accumulated submergence, which are used to demonstrate seasonal trends.

The vertical distributions of conspicuous and easily identified algal species were determined during the following months: May 1966, April 1967, May 1968, 1969, 1970, and July 1971. Observations were made along transects consisting of a taut metered line extending from $2.9 \mathrm{~m}$ to $0.4 \mathrm{~m}$ above 0 tide level. Plants occupying tidepools were ignored.

Changes in the vertical positions of seaweeds yearto-year were assessed using the G statistic (Sokal and Rohlf, 1981). We tested for significant deviation from random change in vertical limits, which we considered to be equal numbers moving up, down, and not changing. The degree of consistency between mean vertical limits of the studied seaweeds on all 3 transects and tidal features was determined using Kendall's coefficient of concordance (Siegal, 1956).

\section{RESULTS}

The major physical difference between the transects was steepness of slope. This was reflected by the linear distances between the $2.9 \mathrm{~m}$ and $0.4 \mathrm{~m}$ tide levels: point, $8 \mathrm{~m}$; channel, $27 \mathrm{~m}$; and flat, $84 \mathrm{~m}$.

Mean monthly wave heights, as determined from recordings taken twice daily during 1966, ranged from $0.5 \mathrm{~m}$ to $1.0 \mathrm{~m}$ (Fig. 1).

The greatest displacement of sea level in response to waves occurred on the point, followed by the channel and the flat (Fig. 2). Tidal curves corrected for wave effects differed from uncorrected tidal curves in 2 ways

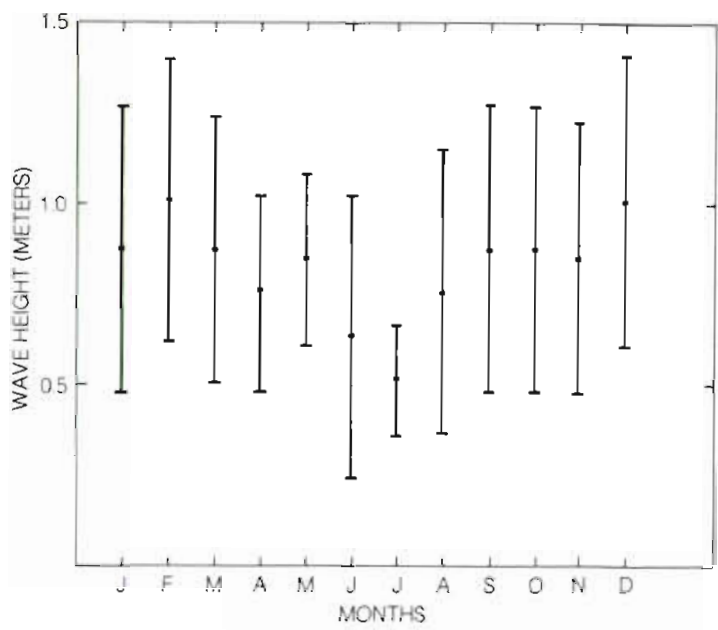

Fig. 1. Monthly means of wave height ( \pm 1 standard deviation) for 1966, as determined from twice-daily observations 


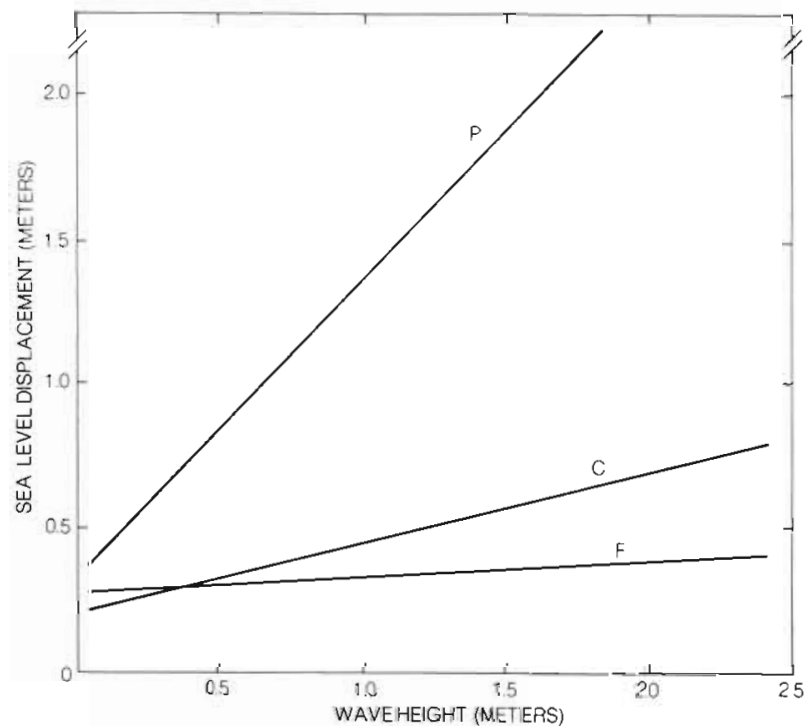

Fig. 2. Sea level displacement as a function of wave height as determined during 1966 for point $(\mathrm{P})$, channel $(\mathrm{C})$, and flat $(\mathrm{F})$

(Fig. 3): the harmonic pattern of the tidal curves tended to be disrupted, and the intertidal range and the lowest level emerged increased from uncorrected tidal curves to the flat, the channel, and the point.

The influence of waves on the various studied tidal features as observed on the 3 transects and compared with tidal data uncorrected for wave effects, are shown in Figs. 4 and 5 and in Table 1 for the May 1 - June 14 period. The tidal features were altered from one extreme value at the point to the other extreme for uncorrected tidal data. For example, the accumulated time submerged at $2 \mathrm{~m}$ above 0 tide was $90 \%$ at the point, $73 \%$ in the channel, $67 \%$ on the flat and $48 \%$ for uncorrected tidal data during this period (Fig. 5). This relation between the transects and the various tidal features remained constant throughout the year, with only the magnitude of the values varying. Fig. 6 illustrates seasonal variation in accumulated time submerged for the point and uncorrected tidal data. The other studied tidal features showed the same seasonal trend.

A general view of the transects revealed several differences in floristic composition. The point contrasted with the other transects in that Postelsia palmaeformis was present, while Phyllospadix scouleri, Egregia menziesii, and bladed and filamentous green algae were absent. The conspicuous differences between the flat and channel were the comparatively low densities of Lessoniopsis littoralis and E. menziesii in the channel.

Most of the plants whose vertical distributions were studied were present throughout the 6-yr observation
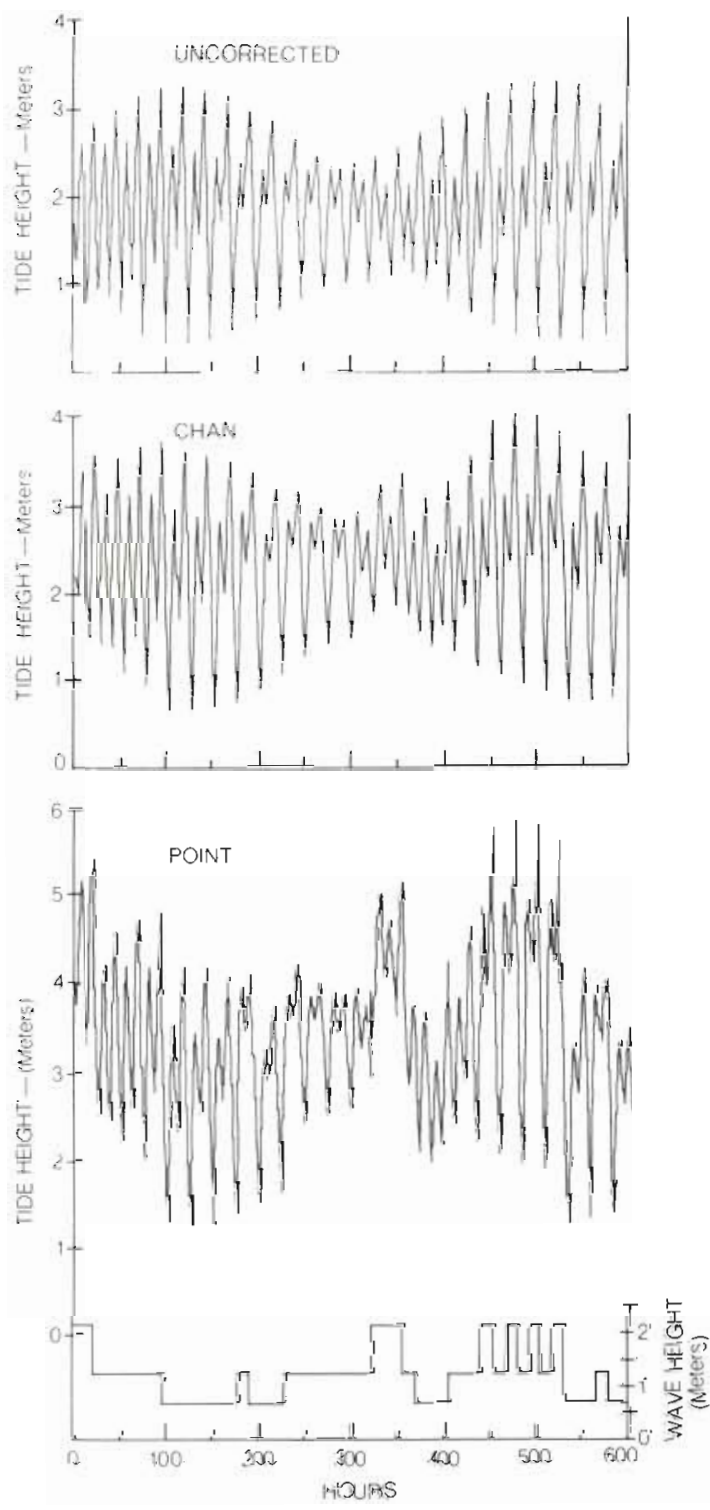

Fig. 3. Tidal curves, corrected for wave effects, for channel and point. The tidal curve for the flat was similar to that of the channel but with slightly less upward displacement. The uncorrected tidal curve is derived directly from 6-min tidal predictions. Wave height data are derived from twice daily observations. All data are for the May 1-25, 1966 period

period (Fig. 7). Two essentially annual algae, Costaria costata and Desmarestia ligulata, were present for only 3 yr on the point and flat respectively, and the perennial alga Egregia menziesii was present in the channel only during the last year of study.

Vertical ranges and means of upper and lower limits observed over the 6-yr study period are shown in Fig. $7_{i}$ the year-to-year changes in vertical limits of selected species, in Fig. 8. Generally, the upper limits of any given species were highest on the point, and 


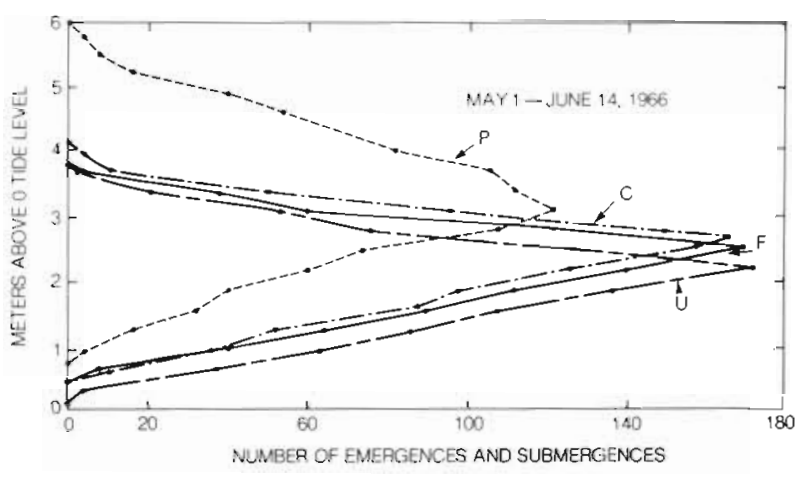

Fig. 4. Total number of emergences and submergences as a function of elevation above 0 tide level for point (P), channel (C), flat (F) and for uncorrected tide data derived directly from 6-min tidal predictions (U)

similar on the flat and channel. Lower limits tended to be lowest on the flat and highest on the point. The ranges of upper and lower vertical limits of individual species varied from a few $\mathrm{cm}$ (e. g. upper limits of Fucus distichus on the channel) to over $1 \mathrm{~m}$ (e. g. upper limits of Hedophyllum sessile on the point) throughout the $6-y x$ study period. The relative vertical positioning between transects also varied; for example, in 1966 Laminaria setchellii was at its highest position on the flat and at its lowest on the channel.

When the relative movement of both upper and lower limits of the studied species on all transects are considered together, some temporal patterns are evident (Table 2). In 1967 and 1969 a significant number of upper and lower limits had lower vertical positions relative to the previous year ( $P \leq 0.029$ ), and between 1969 and 1970 there was an increase in both vertical limits $(P=0.119$ ). During 1968 and 1971 the vertical positioning changed in a random manner $(P \geq 0.404)$.

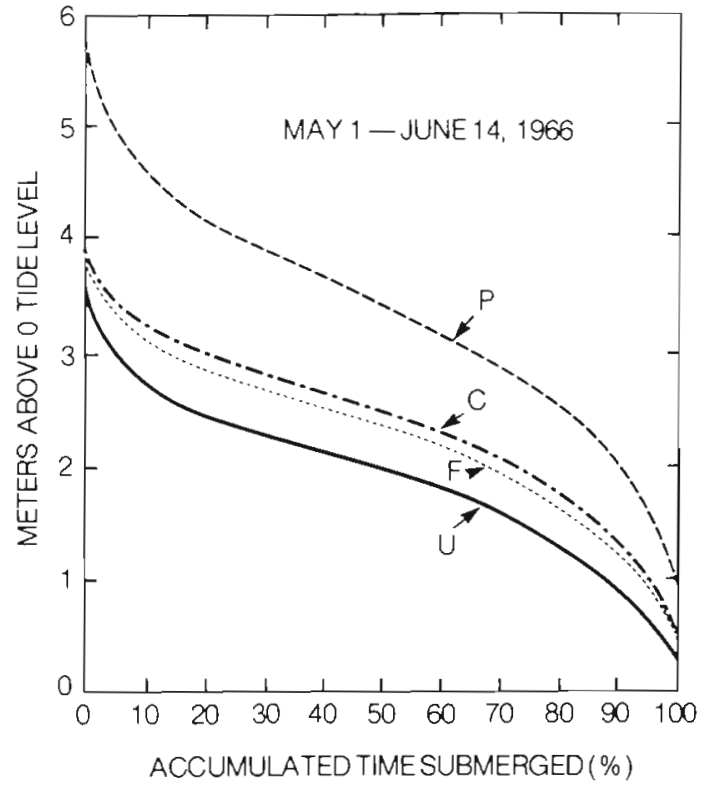

Fig. 5. Accumulated time submerged as a function of elevation above 0 tide level for point $(P)$, channel $(C)$, flat $(F)$ and for uncorrected tide data derived directly from 6-min tidal predictions (U)

The emersion and submersion histories for the mean upper and lower limits of the studied species are given in Table 3. Where there is considerable variation for any one tidal feature between the transects, the extreme value is usually represented by the point (e. $\mathrm{g}$. duration of single greatest emergence for Alaria nana).

As determined by Kendall's coefficient of concordance, the mean upper limits of seaweed distribution were most consistent with accumulated time submerged $(\mathrm{P}=0.059)$, followed by number of emergences and submergences $(\mathrm{P}=0.068)$, duration of

Table 1. Duration of the single greatest emersion (E) and submersion (S) on the 3 transects and from uncorrected tide data. T. F. number of critical tide levels (sensu Doty 1946: levels where a small vertical shift results in a 2-to 3 -fold change in duration of the single greatest emergence or submergence)

\begin{tabular}{|c|c|c|c|c|c|c|c|c|}
\hline \multirow{2}{*}{$\begin{array}{c}\text { Meters above } \\
0 \text { tide }\end{array}$} & \multicolumn{2}{|c|}{ Uncorrected } & \multicolumn{2}{|c|}{ Channel } & \multicolumn{2}{|c|}{ Flat } & \multicolumn{2}{|c|}{ Point } \\
\hline & $\mathrm{E}$ & $\mathrm{S}$ & $\mathrm{E}$ & $\mathrm{S}$ & $E$ & $\mathrm{~S}$ & $\mathrm{E}$ & $\mathrm{S}$ \\
\hline 0 & $0 \mathrm{~h}$ & $1080 \mathrm{~h}$ & $\mathrm{Oh}$ & $1080 \mathrm{~h}$ & $\mathrm{Oh}$ & $1080 \mathrm{~h}$ & $\mathrm{Oh}$ & $1080 \mathrm{~h}$ \\
\hline 0.3 & 0.1 & 700 & 0 & 1080 & 0 & 1080 & 0 & 1080 \\
\hline 0.6 & 0.8 & 260 & 1 & 646 & 1 & 670 & 0 & 1080 \\
\hline 0.9 & 5 & 155 & 3 & 285 & 3 & 259 & 0.6 & 790 \\
\hline 1.2 & 7 & 20 & 4 & 209 & 5 & 160 & 3 & 485 \\
\hline 1.5 & 9 & 18 & 5 & 73 & 6 & 23 & 4 & 357 \\
\hline 1.8 & 15 & 17 & 6 & 36 & 7 & 22 & 5 & 307 \\
\hline 2.1 & 65 & 16 & 8 & 22 & 8 & 18 & 6 & 147 \\
\hline 2.4 & 160 & 5 & 9 & 18 & 18 & 8 & 7 & 145 \\
\hline 2.7 & 255 & 3 & 21 & 8 & 63 & 6 & 9 & 69 \\
\hline 3.0 & 580 & 1 & 87 & 6 & 185 & 5 & 19 & 38 \\
\hline 3.3 & 1080 & 0 & 259 & 4 & 260 & 3 & 21 & 37 \\
\hline T.F. & \multicolumn{2}{|c|}{12} & \multicolumn{2}{|c|}{9} & \multicolumn{2}{|c|}{8} & \multicolumn{2}{|c|}{5} \\
\hline
\end{tabular}




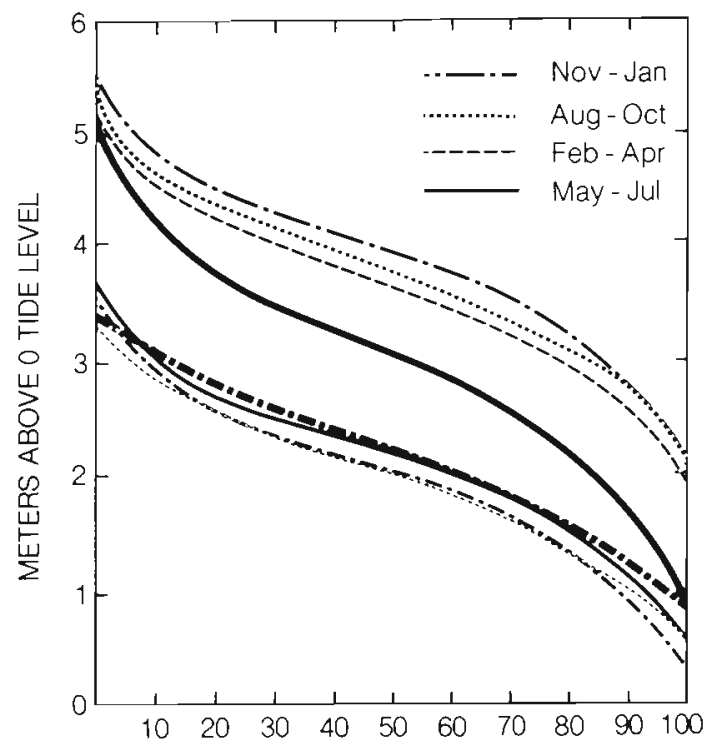

Fig. 6. Seasonal variation in accumulated time submerged as a function of elevation above 0 tide level for 1966. The 4 upper curves represent wave-corrected tidal data for the point; the 4 lower curves are derived directly from 6 -min tidal predictions

Table 2. Percent of upper and lower limits changing upwards $(+)$, downwards $(-)$ or not detectably $(0)$ on the 3 transects between successive years; $n$ : number of cases, as calculated from the $G$ statistic. $P$ assesses the probability that the yearto-year changes were random $(\mathrm{P}=.5$ : random change; $\mathrm{P}<.5$ : increasingly non-random)

\begin{tabular}{|cccccc|}
\hline $1966-1967$ & -1968 & -1969 & -1970 & -1971 \\
\hline \multicolumn{5}{c}{ Change in upper and lower limits } \\
+ & $23.7 \%$ & $36.6 \%$ & $21.7 \%$ & $44.4 \%$ & $35.3 \%$ \\
- & 50.8 & 33.3 & 46.6 & 27.8 & 31.4 \\
0 & 25.5 & 30.1 & 31.7 & 27.8 & 33.3 \\
$\mathrm{n}$ & 59 & 60 & 60 & 54 & 51 \\
$\mathrm{P}$ & 0.011 & 0.404 & 0.029 & 0.119 & 0.471 \\
\hline
\end{tabular}

greatest single emergence $(P=0.075)$ and duration of single greatest submergence $(P=0.212)$. Lower limits were most consistent with duration of greatest single emergence ( $P=0.077$ ) followed by number of emergences and submergences $(P=0.078)$, accumulated time submerged $(\mathrm{P}=0.081)$ and duration of single greatest submergence $(\mathrm{P}=0.085)$.

\section{DISCUSSION}

Three general categories of environmental factors may jointly control the vertical limits of distribution of intertidal organisms: unpredictable disruptions (e. g. storms, abrasion by logs, etc.; Dayton, 1971; Paine
1979), biological interactions (e. g. grazing, crowding, shading, predation; Dayton, 1975), and a differential stress tolerance to intertidal conditions (e. g. desiccation, actinic radiation; Schonbeck and Norton, 1978; Druehl and Hsiao, 1977).

With the exception of the duration of the single greatest submergence or emergence, the various tidal features that have been suggested as significant in determining limits of distributions of intertidal organisms (i. e. total hours of submersion or emersion, and number of submergences and emergences per unit of time) are clinal, and therefore inherently difficult to relate to zonation patterns.

Doty's original field study (1946), a subsequent laboratory study (Doty and Archer, 1950), and a field study by Beveridge and Chapman (1950) supported the hypothesis that the duration of the single greatest emergence or submergence was most important in determining intertidal limits of distribution. Widdowson (1965) and Womersley (1955), however, found no

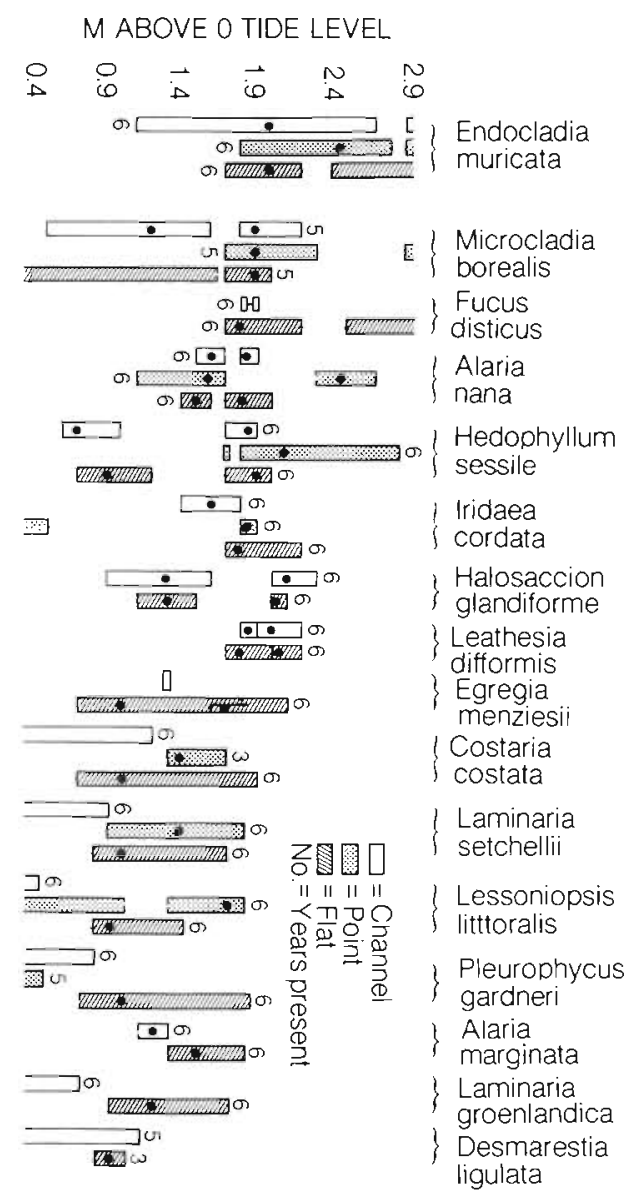

Fig. 7. Vertical ranges (boxes) and means (dots) of the upper and lower limits of selected species on the 3 topographies. Where the range in upper or lower limits exceeded the vertical extent of the beach studied, means were not calculated. These cases are indicated by an open-ended box 
Table 3. Aspects of the emersion and submersion history experienced by the mean upper and lower limits of the studied algae on channel (C), point (P) and flat (F) from May 1 to June 14

\begin{tabular}{|c|c|c|c|c|c|c|c|c|c|c|c|c|}
\hline \multirow[b]{2}{*}{ Mean upper limits } & \multicolumn{3}{|c|}{$\begin{array}{c}\text { Greatest } \\
\text { submergence }(h)\end{array}$} & \multicolumn{3}{|c|}{$\begin{array}{c}\text { Greatest } \\
\text { emergence (h) }\end{array}$} & \multicolumn{3}{|c|}{$\begin{array}{l}\text { Accumulated time } \\
\text { submerged }(\%)\end{array}$} & \multicolumn{3}{|c|}{$\begin{array}{l}\text { Number of } \\
\text { emergences and } \\
\text { submergences }\end{array}$} \\
\hline & $\mathrm{C}$ & $\mathrm{P}$ & F & $\mathrm{C}$ & $\mathrm{P}$ & $\mathrm{F}$ & $\mathrm{C}$ & $\mathrm{P}$ & $F$ & C & $\mathrm{P}$ & $\mathrm{F}$ \\
\hline Hedophyllum & 31 & 149 & 20 & 7 & 6 & 8 & 77 & 89 & 71 & 97 & 53 & 113 \\
\hline Iridaea & 61 & 253 & 22 & 5 & 6 & 7 & 85 & 92 & 77 & 82 & 39 & 104 \\
\hline Alaria nana & 31 & 138 & 22 & 7 & 35 & 7 & 76 & 83 & 74 & 95 & 72 & 106 \\
\hline A. marginata & 188 & & 23 & 4 & & 6 & 92 & & 82 & 49 & & 87 \\
\hline Microcladia & 32 & & 21 & 7 & & 8 & 76 & & 73 & 98 & & 112 \\
\hline Halosaccion & 22 & & 17 & 8 & & 8 & 70 & & 66 & 119 & & 129 \\
\hline Leathesia & 27 & & 18 & 7 & & 8 & 72 & & 65 & 111 & & 130 \\
\hline Egregia & 209 & & 22 & 4 & & 7 & 93 & & 78 & 45 & & 100 \\
\hline \multicolumn{13}{|l|}{ Mean lower limits } \\
\hline Endocladia & 27 & 100 & 20 & 7 & 7 & 10 & 72 & 83 & 67 & 110 & 76 & 125 \\
\hline Alaria nana & 61 & 307 & 23 & 5 & 4 & 6 & 83 & 95 & 79 & 82 & 32 & 83 \\
\hline Hedophyilum & 526 & 324 & 256 & 2 & 5 & 3 & 98 & 94 & 95 & 18 & 90 & 30 \\
\hline Halosaccion & 141 & & 92 & 5 & & 6 & 91 & & 86 & 58 & & 68 \\
\hline Leathesia & 31 & & 22 & 7 & & 7 & 78 & & 79 & 101 & & 103 \\
\hline Fucus & 26 & & 22 & 6 & & 7 & 78 & & 74 & 97 & & 104 \\
\hline
\end{tabular}

correlation between vertical distributions and durations of single greatest emergences or submergences. Doty (1957) continued to support his original hypothesis, but concluded that use of this tidal feature was too complex to be practical. More recently, Chapman (1973) dismissed tidal features as being unimportant in delineating intertidal distributions.

Generally, earlier studies have calculated the submersion/emersion history of a shore from predicted or
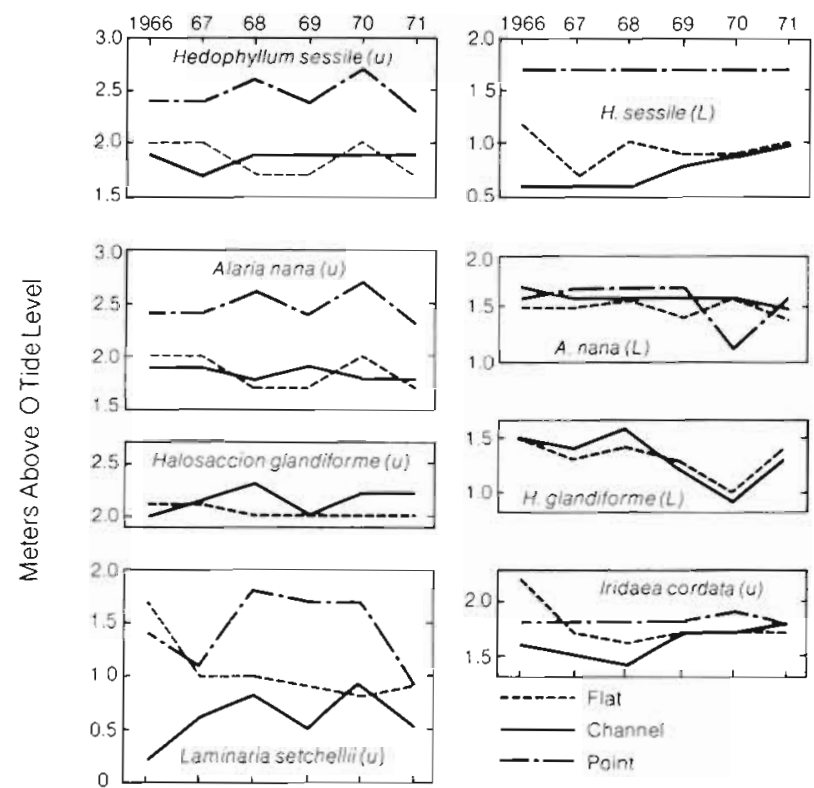

Fig. 8. Year-to-year variation of the upper (U) and lower (L) limits of selected species recorded tidal data (e. g. Doty, 1946; Womersley, 1955; Widdowson, 1965). In a few instances, the elevation of tides by waves was noted by either measuring wave excursions up the shore (e. g. on 2 occasions for $10 \mathrm{~min}$; Atobe and Saito, 1974), or by observing sea level during calm sea conditions against a tidal pole positioned near shore (Beveridge and Chapman, 1950). Our data show that these approaches fail to describe accurately the submersion/emersion history of the intertidal region, insofar as they do not account for wave conditions over an extended period, or for the influence of local topographic features. Our approach of adjusting tidal heights on 3 adjacent intertidal transects on the basis of observations made twice daily for a year, and on empirically derived relations between topography and wave excursions, enabled us to calculate realistic submersion/emersion histories for our study transects.

Our data demonstrate that wave action causes substantial changes in actual submersion/emersion events from those predicted from tidal data, and the extent of these changes is dependent upon topography and season. The steeper the slope, the higher the position of any particular tidal feature, and maximum differences between actual and predicted submersion/emersion events occur at those times of year when wave heights are greatest. Any attempt to describe accurately the submersion/emersion history of a shore must therefore account for these 2 variables. We are not familiar with any studies which have done this with sufficient accuracy to test validly Doty's tide factor hypothesis, or other hypotheses directly related to submersion/emersion events. 
Previous attempts to relate intertidal distributions to the submersion/emersion history of the intertidal zone have relied on single observations of the vertical limits of distributions (e. g. Doty, 1946). Other studies have demonstrated a seasonal change in vertical limits of intertidal plants (Lawson, 1957; Druehl and Hsiao, 1977; Schonbeck and Norton, 1978), but to our knowledge variation in vertical limits over several years has not been reported. We have found that in some instances, limits of vertical distribution over the 6 -yr study period ranged to over $1 \mathrm{~m}$ (or over $1 / 3$ of the maximum tidal amplitude).

Generally the upper and lower limits were higher on the point than on the flat or channel. Earlier studies have correlated an elevation of vertical limits with increasing wave exposure, and hypothesized that this reflected a differential submersion/emersion history at any one tidal level between sites of different wave exposure (Atobe and Saito, 1974; Lewis, 1977). Our study has shown that marked differences in vertical positioning can occur along a short $(50 \mathrm{~m})$ horizontal stretch of coast with the same wave exposure, and that these are related to topography. Widdowson (1965) noted that there was greater variability in vertical distributions on surf-exposed coasts; we contend that this variability is a function of the local topography.

Vertical floristic patterns changed between years, as well as between the 3 topographies. The vertical limits of a single species sometimes changed differentially in a given year (e. g. up on the point and down on the flat), yet there was a general tendency for the majority of species to alter their limits in a common mode from year to year. When looked at individually, most of the species experienced similar submersion/emersion histories, particularly accumulated time submerged and duration of the single greatest emergence at the mean limits of their vertical distribution on the 3 topographies. These results suggest the presence of a common factor(s) whose stress/benefit effects on the vertical limits of the plants vary from year to year, but for any one year have a more or less uniform effect.

A variety of studies have shown that abiotic factors associated with an intertidal position can limit the vertical distribution of marine plants. Observations on post-earthquake shores of Alaska demonstrated that moderately uplifted intertidal communities could not survive at a higher intertidal level, but that communities which were shifted downward could survive at their new position (Haven, 1971). Further, transplant studies on intertidal fucoids have demonstrated that the upper limits of 2 Fucus species are determined by physical factors (Schonbeck and Norton, 1978). The effects of a tidal cycle on intertidal fucoid growth, as observed under laboratory conditions, suggest an emersion requirement for these plants (Rusanowski and Vadas, 1973; Schonbeck and Norton, 1979). Edwards (1977), however, questions the general applicability of these observations.

Our detailed and long-term observations of wave and tide heights on 3 adjacent transects have shown that the actual submersion/emersion patterns along a shore deviate considerably from standard tide predictions, and these differences are the result of local topography. Observations of algal distribution on the 3 transects over 6-yr period proved to correlate with certain aspects of the submersion/emersion history of each location, indicating that submersion/emersion events do indeed play an important role in determining vertical distributions of intertidal seaweeds.

Acknowledgements. We wish to thank Professor N. J. Wilimovsky for the use of his Port Renfrew facilities and his continued interest in this project. Ms. K. Lloyd assisted in the preparation of this manuscript and Mr. E. Cabot performed the statistical analyses. Funding was provided by the National Research Council of Canada.

\section{LITERATURE CITED}

Atobe, S., Saito, Y. (1974). Phytosociological study of the intertidal marine algae. III. Effect of wave action on algal zonation. Bull. Fac. Fish. Hokkaido Univ. 24: 133-138

Beveridge, W. A., Chapman, V. J. (1950). The zonation of marine algae at Piha, New Zealand, in relation to the tidal factor (studies in intertidal zonation 2). Pacif. Sci. 4: 188-201

Carefoot, T H. (1977). Pacific seashores: a guide to intertidal ecology. J. J. Douglas, Vancouver

Chapman, A. R. O. (1973). A critique of prevailing attitudes towards the control of seaweed zonation on the sea shore. Botanica mar. 16: 80-82

Connell, J. H. (1961). The influence of interspecific competition and other factors on the distribution of the barnacle Chthamalus stellatus. Ecology 42: 710-723

Dayton, P. K. (1971). Competition, disturbance and community organization: the provision and subsequent utilization of space in a rocky intertidal community. Ecol. Monogr. 41: $351-389$

Dayton, P. K. (1975). Experimental evaluation of ecological dominance in a rocky intertidal algal community. Ecol. Monogr. 45: 137-159

Doty, M. S. (1946). Critical tide factors that are correlated with the vertical distribution of marine algae and other organisms along the Pacific coast. Ecology 27: 315-328

Doty, M. S. (1957). Rocky intertidal surfaces. Mem. geol. Soc. Am. 67: 535-585

Doty, M. S., Archer, J. G. (1950). An experimental test of the tide factor hypothesis. Am. J. Bot. 37: 458-464

Druehl, L. D., Green, J. M. (1970). A submersion-emersion sensor for intertidal biological studies. J. Fish. Res. Bd Can. 27: 401-403

Druehl, L. D., Hsiao, S. I. C. (1977). Intertidal kelp response to seasonal environmental changes in a British Columbia Inlet. J. Fish. Res. Bd Can. 34: 1207-1211

Edwards, P. (1977). An investigation of the vertical distribution of selected benthic marine algae with a tide-simulating apparatus. J. Phycol. 13: 62-68 
Haven, S. B. (1971). Effects of land-level changes on intertidal invertebrates, with discussion of post earthquake ecological succession. In: The great Alaska earthquake of 1964 ; Biology. Nat. Acad. Sci. pp. 82-126

Hewatt, W. G. (1937). Ecological studies on selected marine intertidal communities of Monterey Bay, California. Am. Midl. Nat. 18: 161-206

Jones, W. E., Demetropoulos, A. (1968). Exposure to wave action: measurements of an important ecological parameter on rocky shores on Anglesey. J. exp. mar. Biol. Ecol. 2: $46-63$

Lawson, G. W (1957). Seasonal variation of intertidal zonation on the coast of Ghana in relation to tidal factors. J. Ecol. 45: 831-860

Lewis, J. R. (1964). The ecology of rocky shores, English University Press, London.

Lewis, J. R. (1977). The role of physical and biological factors in the distribution and stability of rocky shore communities. In: Keegan, B. F., Ceidigt, P. O., Boaden, P. T. S. (eds.) Biology of benthic organisms. 11th European Symposium on Marine Biology, Galway, 1976. Pergamon Press, Oxford, pp. 417-424

Lubchenco, J. (1980). Algal zonation in the New England rocky intertidal community: an experimental analysis. Ecology 61: 333-344

Paine, R. T. (1979). Disaster, catastrophe, and local persistence of the sea paim Postelsia palmaeformis. Science, N. Y. 205: 685-687
Paine, R. T., Vadas, R. L. (1969). The effects of grazing by sea urchins, Strongylocentrotus spp. on benthic algal populations. Limnol. Oceanogr. 14: 710-719

Rusanowski, P. C., Vadas R. L. (1973). A tide simulating apparatus for the study of intertidal marine algae (abstract). Bull. ecol. Soc. Am. 54: 35

Schonbeck, M., Norton, I A. (1978). Factors controlling the upper limits of fucoid algae on the shore. J. exp. mar. Biol. Ecol. 31: 303-313

Schonbeck, M., Norton, T. A. (1979). The effects of brief periodic submergence on intertidal fucoid algae. Estuar. coast. mar. Sci. 8: 205-211

Siegal, S. (1956). Non-parametric statistics for the behavioral sciences, McGraw-Hill, New York

Sokal, R. R., Rohlf, F. J. (1981). Biometry, 2nd ed., W. H. Freeman, San Francisco

Underwood, A. J. (1978). A refutation of critical tidal levels as determinants of the structure of intertidal communities on British shores. J. exp. mar. Biol. Ecol. 33: 261-276

Widdowson, T. B. (1965). A survey of the distribution of intertidal algae along a coast transitional in respect to salinity and tidal factors. J. Fish. Res. Bd Can. 22: $1425-1454$

Womersley, H. B. S. (1955). The marine algae of Kangaroo Island. IV. The algal ecology of American River Inlet. Aust. J. mar. freshwat. Res. 7: 63-87

This paper was presented by Professor R. L. Haedrich; it was accepted for printing on April 23, 1982 